\title{
Educating Pre-service Teachers in Technology Use: A Study of Provision at Lebanese Universities
}

\author{
Youmen Chaaban ${ }^{1, *} \&$ Robyn Moloney ${ }^{2}$ \\ ${ }^{1}$ College of Education, Qatar University, PO Box 2713, Doha, Qatar \\ ${ }^{2}$ School of Education, Macquarie University, PO Box 2109, NSW, Australia \\ *Correspondence: College of Education, Qatar University, PO Box 2713, Doha, Qatar. Tel: \\ 974-3045-3480. E-mail: ychaaban@qu.edu.qa
}

Received: March 18, 2016 Accepted: April 20, 2016 Published: May 14, 2016

doi:10.5296/ije.v8i2.9188ＵRL: http://dx.doi.org/10.5296/ije.v8i2.9188

\begin{abstract}
In order to better prepare pre-service teachers to teach with technology, the purpose of this qualitative study was to investigate the current practices and barriers in technology preparation at seven Lebanese education programs. The study used in-depth interviews, document analysis and examination of artifacts to investigate the conditions met, strategies adopted, approaches integrated and content goals pursued within the broader context of a representative sample of Lebanese universities. The participants were seven university lecturers who were responsible for pre-service teachers' educational technology preparation. Findings revealed inconsistent technology integration across the programs. A number of factors hindered a systematic implementation of technology integration, including insufficient training, combined strategies, technology access, shared vision, mastery and vicarious experiences, faculty development, focus on content area or grade level, and ongoing assessment. The paper outlines the implications for teacher preparation programs and offers suggestions for the better preparation of pre-service teachers.
\end{abstract}

Keywords: Pre-service teacher preparation, Strategies, Approaches, Barriers, Lebanon 


\section{Introduction}

It is widely recognized that pre-service teacher technology preparation is a critical component of improving the quality of education for the future (Choy, Wong, \& Gao, 2009). Not only must pre-service teachers learn how to operate the technology, they must also learn how to integrate it into quality teaching and learning. To accomplish this, teacher educators need to design programs conducive to effective technology integration and create a rich environment for tomorrow's technology-using teachers and their students. Many universities worldwide have responded to this necessity by introducing technology preparation into their teacher education settings in several different forms (Hsu, 2012).

In 2012, Lebanon's National Educational Technology Strategic Plan emphasized the need "to review and improve recruiting, preparing, supporting, and compensating teachers on the pre-service front end rather than fixing issues of poor-quality instruction on the in-service back end” (MEHE, 2012 p. 83). However, little is known about the educational technology courses offered at the various Lebanese universities and their effectiveness in preparing pre-service teachers to integrate technology in their future teaching (Saleh, 2007). Even though previous studies have examined the factors that hinder teacher technology preparation and have offered implications for practice, several studies have shown that teachers feel unprepared to teach with technology (Tondeur et al., 2012). Therefore, it is important to examine the challenges that still affect technology use and offer new visions for the future preparation of teachers in a unique educational context.

The current study investigated university courses at both the public university and other private universities in Lebanon to provide a description of their structure and content as well as to identify the presence of barriers. The findings of the study may guide other teacher education programs as they redesign learning experiences for their pre-service teachers. The research thus outlines recommendations for teacher preparation programs, which may enhance the effectiveness of their strategies and approaches to technology implementation.

\section{Literature Review}

A framework proposed by UNESCO (2002), and studies by Kay (2006), and Ottenbreit-Leftwich, Glazewski, and Newby (2010) have variously developed models for teacher preparation programs identifying strategies, approaches, and content goals which need to be in place for the successful integration of educational technologies.

\subsection{Strategies Adopted by Universities}

The ten strategies identified by Kay (2006) provide universities with options to develop courses that best fit their contexts. These strategies take ten different forms: (1) single technology courses, (2) mini-workshops, (3) full integration, (4) modeling, (5) using multimedia, (6) collaboration, (7) field-based, (8) focus on education faculty, (9) focus on mentor teachers, and (10) focus on access to software, hardware, and/or support. Whichever the strategy, the ultimate goal is for pre-service teachers to acquire and then transfer 


\section{Macrothink

knowledge and skills into their teaching practices (Brush et al., 2003). To ensure that teachers are well-prepared for technology integration, researchers have agreed that technology training should be integrated throughout the teacher preparation program (Tondeur et al., 2012).

According to Kay's (2006) study, 44\% of the programs investigated adopted the integrated strategy, which has a clear focus on meaningful and authentic problem-solving tasks. As pre-service teachers learn with computers, they acquire an increasingly complex skill repertoire (Collier, Weinburgh, \& Rivera, 2004). By contrast, 29\% of the programs were delivering a single technology course that targeted basic computer skills. The primary advantages of this strategy were improving self-efficacy, enhanced value beliefs, and developing a strong foundation of technology skills (Lambert, Gong, \& Cuper, 2008). The major disadvantages of this strategy included learning technology skills in isolation and the limited extension of these skills in the field (Choy, Wong, \& Gao, 2009). Other concerns included a mismatch between the technology requirements of the courses and incoming student teachers' skills, a disconnection between technology skills and teaching methods, and indecision of when the course should be taken (Wang, 2006). A single technology course strategy might be effective for one-year programs, rather than multi-year programs, however, "the jury is still out on which strategies work best" (Kay, 2006 p. 395).

Kay's (2006) model is useful in evaluating the comprehensiveness of the technology integration strategy adopted within teacher preparation programs. According to Figure 1, having good access to software, hardware, and support is the first requisite in the university classroom and the field placement. Without adequate access, other strategies will not find a fertile context. Next, whether the strategy adopted is the single course, workshop, integration, or multimedia strategy, the program must be accompanied with every effort to model and construct authentic teaching activities. Finally, collaboration among pre-service teachers, faculty members and mentor teachers is deemed necessary if gains in attitude and ability are to translate into meaningful uses of technology. Considering the diversity within university technology programs, it is clear that 'a one size fits all' course is neither possible nor necessary. 


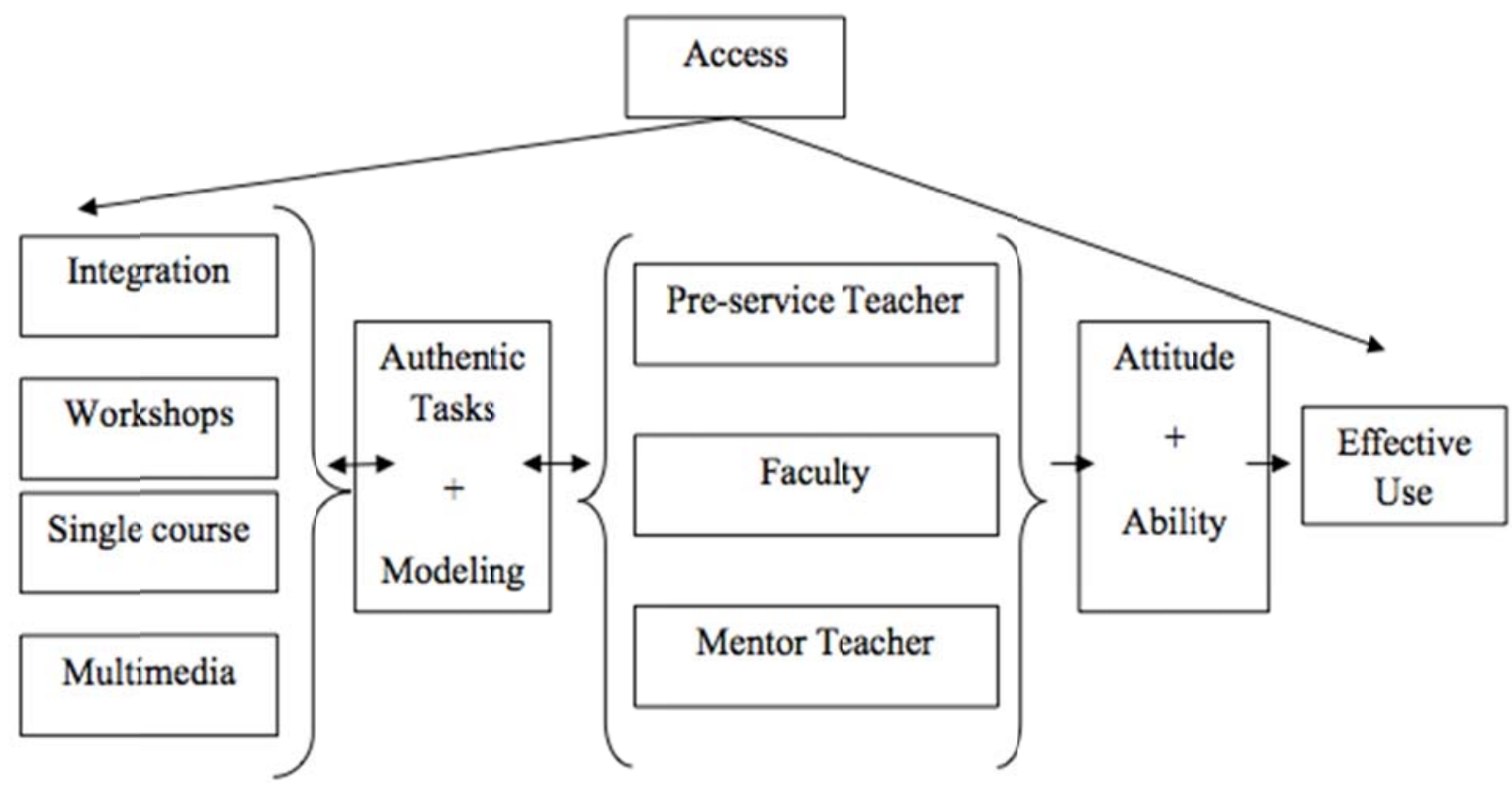

Figure 1. Kay’s Model for Strategies Adopted during Pre-Service Teacher Educational Technology Preparation

\subsection{Approaches and Content Goals within the Broader University Context}

On an individual course level, Ottenbreit-Leftwich et al. (2010) identified six approaches used in preparing teachers to integrate technology whatever the strategy adlopted. They are: (1) information delivery of technology integration content, (2) hands-on technology skill building activities, (3) practice with technology integration in the field, (4) technology integration observation or modeling sessions, (5) authentic technology integration experiences, and (6) technology integration reflections. The researchers dlescribe the process used to design technology experiences for pre-service teachers and provide faculty with various experiences to select from according to the intended goals of the program. The activities identified are separated into three main constructs: the specific methods used to conduct the activities (approaches), the substance or curriculum covered in the activities (technology content goals), and how the activities are situated in the overall teacher education curriculum (broader context).

\subsection{Conditions for Effective Technology Integration}

Several organizations have developed comprehensive standards and components that should be met throughout the university program (ISTE, 2008; Partnership for $21^{\text {st }}$ Century Skills, 2010; UNESCO, 2002). Acknowledging and measuring up to these standards, universities can ensure that teacher preparation courses are adequately preparing future teachers. The framework proposed by UNESCO (2002) comprises ten essential conditions as follows: shared vision, access, skilled educators, professional development, technical assistance, content standards and curriculum resources, student-centered teaching, assessment, community support and support policies. 


\section{Methodology}

This study used a qualitative research methodology. The exploratory nature of the study allowed for in-depth descriptions of the course contexts. Creswell (2013) supports the use of exploratory studies especially when "not much has been written about the topic or the population being studied” (p. 29). In order to understand how to better prepare pre-service teachers to integrate technology in their classrooms, this qualitative study uses these viewpoints of strategies, approaches, content goals, broader context and conditions for effective integration to examine the current practices and barriers in technology integration at seven Lebanese teacher preparation programs. The research questions were: (a) What are the current practices implemented to prepare pre-service teachers to integrate technology into their classrooms? (b) What barriers can be identified in the shaping of the pre-service teacher preparation programs? and (c) What implications do these practices and barriers offer to better prepare pre-service teachers?

\subsection{Description of Participants}

The selection process began by identifying all the universities in Lebanon that housed an Education department and where the language of instruction was English. Eleven universities met the criteria of inclusion in this study. The university lecturers who taught the educational technology courses were approached via email, and seven teacher educators agreed to participate in the study. There were 6 females and one male participant. Participants' teaching experience ranged from 2 to 13 years, and their ages ranged from 33 to 52 years.

\subsection{Data Collection}

Participants were interviewed for 50 minutes using a semi-structured interview protocol. The questions targeted course structure, objectives and expected outcomes, available infrastructure, student participation and activities. Both open-ended and closed-ended questions were included in the interview protocol in order to provide a quick and succinct means of comparing data across the seven universities. Further data was collected in the form of the course syllabus and artifacts made by some of the pre-service teachers who had taken the course. These secondary data sources provided a means for triangulation and validation of the interview data. Following data collection, interviews were transcribed and returned to the participants for member checking.

\subsection{Data Analysis}

To answer the research questions, the interview data were analyzed as cross-case comparisons, rather than as university-level case studies. Using the constant comparative model (Denzin \& Lincoln, 1998), a search for themes was conducted related specifically to the theoretical framework adopted in the study. As each program was analyzed, the course requirements and structure were compared to the recognized essential conditions for effective pre-service teacher preparation. Themes could be constantly compared as they emerged directly from the data. The data obtained from the interview with the lecturers was further analyzed for barriers to identify challenges facing successful implementation of technology. Several recommendations are offered for teacher preparation programs to support and improve their strategies and approaches. 


\section{Findings}

All participating universities were found to integrate technology into their programs through the single course strategy. However, they differed in the types of approaches integrated and the kinds of technology content goals pursued, both of which led to different course requirements and learner activities. Further, a number of factors were identified to hinder the preparation of pre-service teachers. These current practices and factors offer implications to support teacher education programs in their technology preparation efforts.

\subsection{Strategies Adopted in the Educational Technology Courses}

The seven university courses investigated provided their pre-service teachers with technology training using the single course strategy. Accordingly, the preparation of pre-service teachers took place through an isolated course among several other courses that constituted the program. In addition to the single course strategy, four universities further adopted two or three other strategies.

\subsubsection{The Education Faculty Strategy}

Two universities focused on improving the attitudes, abilities and use of technology, offering education faculty workshops targeting technological skills. The workshops held at university A and E followed a similar pattern. Both involved training university professors in generic technological applications such as Moodle, Blackboard, the library catalogue, and Turn It In software. Both lecturers also agreed that the support was helpful and ongoing.

Other lecturers were either dissatisfied with the support provided or such support was lacking. Teacher educators were required to possess the necessary technological skills and their individual effort to acquire these skills was commended (UB and UG). Dissatisfaction with the support indicated several challenges that rendered the professional development ineffective. Among these challenges were the small-scale participation, unpreparedness of participants and language barriers.

Someone from the British Council came from London 3-4 years ago and we asked some of the instructors to attend this workshop and it was a week long. They taught them how to use technology in teaching, but whether it was effective or not, whether they are using it or not, I don't know. Some professors, say 15-18 attended and not everybody was ready for it. The instructor who came was speaking English and not all the teachers understand English. (UG50-54)

\subsubsection{The Multimedia Strategy}

Only one lecturer mentioned the multimedia strategy in the form of case studies presenting examples of technology being used in real classrooms. This strategy offers similar advantages to the modeling strategy, yet the mode of presentation is electronic rather than in real-time.

\subsubsection{The Access Strategy}

All seven lecturers stated having access to a variety of technological tools and resources. However, they differed in the quantity of resources available. A summary of the resources 
available at these universities is presented in Table 1.

Table 1. Technological Equipment Available for the Courses Investigated (N=7)

\begin{tabular}{lllllllll}
\hline Technological device & UA & UB & UC & UD & UE & UF & UG \\
\hline 1- PCs & A & A & A & A & A & A & A \\
2- IWB & A & A & X & X & X & X & A \\
3- Video conferencing & A & A & A & A & X & A & X \\
4- Audio equipment & A & A & A & A & A & A & A \\
5- Digital cameras & A & A & X & X & X & A & X \\
6- Digital video cameras & A & A & X & X & X & A & X \\
7- Projection system & A & A & A & A & A & A & A \\
\hline
\end{tabular}

A: Availability of technological device; X: Unavailability of technological device

Two universities placed particular emphasis on the access strategy. These universities were fully equipped with all necessary devices and software. The other universities possessed more limited resources. One technological device of particular interest to the educational arena nowadays is the interactive whiteboard (Campbell \& Kent, 2010). This technological device was among the least available technological tools.

\subsubsection{The Collaboration, Field-Based and Mentor Teacher Strategies}

According to Kay's (2006) model, the standalone educational technology course excludes the possibility of training pre-service teachers through the integrated and workshop strategies. However, the single course strategy is quite compatible and should be enhanced with the collaboration, field-based, and/or mentor teacher strategy through modeling and/or authentic activities. None of the universities conducted the field-based component of their program with a particular emphasis on technology.

One participant expressed a relative situation in regards to field-based technology integration. Using technology was not compulsory and depended on the school and the cooperating in-service teachers.

If they are placed in a school that is technology oriented, definitely they will use technology in their practice teaching, if they are in a school that is not equipped or doesn't have any use of ICT; there is no requirement for them to do so. It depends on the logistics whether they can order a computer with a projection to do their practice teaching, or whether the school has a computer lab. (UE66-69)

Since a field-based component associated with the single course strategy was missing at all the university programs, the mentor teacher strategy became impractical. There were no formal requirements for mentor teachers to integrate technology during student teachers' field placements.

According to participant E, there was a high possibility that mentor teachers were incorporating technology during student teachers' field experiences at technology-equipped 
schools.

We can't impose this on the schools. But we select the schools in which our students do their practice. The schools that we select are updated schools and they do use technology in their teaching. (UE72-73)

\subsection{Approaches, Content Goals and the Broader Context of the Educational Technology Courses}

A variety of approaches and technology content goals were registered at the seven universities. Among the most common approach mentioned was the authentic experiences approach noted at five universities followed by the information delivery approach noted at four universities. Using these approaches among others, the lecturers taught a variety of technology content goals. The broader context of these universities was similar in that the preparation of pre-service teachers took place through one or more isolated courses.

\subsubsection{Approaches to Technology Integration}

Five universities provided technology training through authentic experiences. They taught with technology as opposed to teaching about technology. Two of these university courses could be described as consisting of a problem-based component. Pre-service teachers were required to locate an educational problem and then using specific technological tools, they mapped out a solution.

I teach my students how to use a wiki and to work in a group to search for a project and they have to implement an activity using the tool such as raising awareness about pollution, obesity, alcohol... they learn not only how to use the tools but even using educational approaches. (UA22-25)

We start with a global thing like when we work on Excel, I put a problem: you have a certain amount of money to go shopping and you have a list of items with the prices. Some of them are discounted, some of them are not and you are limited with this amount of money. Build a model on Excel that will tell you when you exceed your budget and give you a kind of alarm that you are exceeding and that will help you reconsider your shopping items in a way to remain in this. (UE127-131)

Still within the authentic experiences approach, five universities used a project-based approach. Pre-service teachers completed educational projects using specific technological tools. Projects included unit/lesson plans, website evaluations, picture mounting, bulletin board design, grade books, online test building, blogs and wikis.

The authentic experiences approach was also manifested at two universities through simulations of field activities conducted in the computer lab. Pre-service teachers taught the lessons they had prepared using technology to their peers in a simulated classroom context.

They take the role of the students and the teachers. They do the project that the students are supposed to take in the class. They do a dual work as if they are teachers and they want to teach their students. (UF16-18) 


\section{Macrothink

Four universities also incorporated the information delivery approach, which refers to the way the instructor delivers important information on specific technology integration content. Within this approach, two universities included readings through a prescribed book as a component of the course.

Currently we are using a Pearson textbook. They do some readings; they use it as a reference for developing their lessons, or for ideas for the history of computers or the components of a computer system for school. (UE33-35)

Also under the information delivery approach, two other universities depended upon lectures as a method of conveying information. Finally, three universities used the hands-on skill building activities approach to help pre-service teachers acquire the necessary technical skills for technology integration. However, it was used as the sole approach at university D.

And part of this course is how to use the computer, if a student has any problem using the computer a minimum troubleshooting for the teacher how to handle this problem...And after when they start practicing the computer, I gave them projects for PowerPoint, and for just to give me information about Activeboard (UD10-17)

\subsubsection{Technology Content Goals Targeted}

In terms of technology content goals, Microsoft Office software was common to all seven programs. The presentation tool, MS PowerPoint, was the most cited generic software used by teacher educators and pre-service teachers. Further, web 2.0 tools were mentioned at four universities. With interactive whiteboards at only three universities, teachers were trained to use the Activinspire software, which accompanies this device at only one university. Less common technology content goals included: Google Sites, Google docs, Moviemaker, Photoshop, Dream Weaver, Paintshop, Picasa, Audacity, LOGO, Hot Potatoes and Moodle.

\subsection{Essential Conditions for the Integration of Technology}

According to the essential conditions for implementing technology in teacher education (UNESCO, 2002), all participants alluded to the presence of several essential conditions. Three conditions were in place at all seven universities. These included the importance of access, skilled educators, and technical assistance. The condition of learning through student-centered methods was addressed at five universities. However, none of the courses met all ten essential conditions necessary for the creation of a supportive environment at the university level. Table 2 presents a summary of the conditions that were in place at these universities. 
Table 2. Presence of the Essential Conditions within the Courses Investigated (N=7)

\begin{tabular}{|c|c|c|c|c|c|c|c|}
\hline Conditions & UA & UB & UC & UD & UE & UF & UG \\
\hline 1- Shared vision & $\mathrm{A}$ & $\mathrm{X}$ & $\mathrm{X}$ & $\mathrm{X}$ & $\mathrm{X}$ & $\mathrm{X}$ & $\mathrm{A}$ \\
\hline 2-Access & $\mathrm{A}$ & $\mathrm{A}$ & $\mathrm{A}$ & A & A & A & A \\
\hline 3- Skilled educators & $\mathrm{A}$ & $\mathrm{A}$ & $\mathrm{A}$ & $\mathrm{A}$ & $\mathrm{A}$ & $\mathrm{A}$ & A \\
\hline 4- Professional Development & $\mathrm{A}$ & $\mathrm{X}$ & $\mathrm{X}$ & $\mathrm{X}$ & A & $\mathrm{X}$ & $\mathrm{X}$ \\
\hline 5- Technical assistance & $\mathrm{A}$ & $\mathrm{A}$ & $\mathrm{A}$ & A & A & A & A \\
\hline 6- Content standards & $\mathrm{X}$ & $\mathrm{A}$ & $\mathrm{X}$ & $\mathrm{X}$ & A & A & $\mathrm{X}$ \\
\hline 7- Student centered & A & $\mathrm{A}$ & $\mathrm{A}$ & $\mathrm{X}$ & A & $\mathrm{A}$ & $\mathrm{X}$ \\
\hline 8- Assessment & $\mathrm{x}$ & $\mathrm{x}$ & $\mathrm{X}$ & $\mathrm{x}$ & $\mathrm{X}$ & $\mathrm{X}$ & $\mathrm{x}$ \\
\hline 9- Community support & $\mathrm{X}$ & $\mathrm{X}$ & $\mathrm{X}$ & $\mathrm{X}$ & $\mathrm{X}$ & $\mathrm{X}$ & $\mathrm{X}$ \\
\hline 10- Support policies & $\mathrm{X}$ & $\mathrm{X}$ & $\mathrm{X}$ & $\mathrm{X}$ & $\mathrm{X}$ & $\mathrm{X}$ & $\mathrm{X}$ \\
\hline
\end{tabular}

A: Condition met; X: Condition not met

Two universities mentioned the presence of a shared vision with another committee and IT office, which were responsible for system wide technology integration. At the other universities, commitment to technology integration seemed to be at the course level, rather than at the system level.

There is a committee, we have the coordinator of the committee and members. The members could be instructors and IT staff as well. The job of the committee is to provide the Dean with the most important software; pedagogical and other, the equipment that we need, if there is any problems, if there is a need for training. (UG69-72)

The second condition, access, was a strategy adopted by all seven universities, though in varying degrees. Two universities in particular were highly equipped with technological devices. Though access was more or less available at the universities participating in the study, only one university mentioned the presence of technology at the schools where pre-service teachers conducted their field placements.

In regards to the third essential condition, skilled educators, all participants were skilled educators in technology and its applications in education. All participants believed they possessed high levels of technology expertise. Beyond the use of PowerPoint as a presentation tool, little can be said about the other teacher educators working at the different departments of education.

There is encouragement for everybody to use technology but this is not mandatory. (UE56-57)

Two universities met the fourth condition of providing professional development to education faculty. Professional development was provided to all teacher educators at these two universities through the workshop strategy. At the other universities, teacher educators were not aware of the availability of workshops.

Technical assistance was provided at all seven universities. It was offered informally to the other teacher educators upon their request. 
We have IT people in each branch, so if we have problems and we do have a lot of problems because all the students use the computers, but we really need more IT support because of the problems. (UG47-48)

Three universities seemed to be aware of the fifth condition, content standards and curriculum resources particular to certain subjects. Two of these universities required simulations of field-based experiences by having their pre-service teachers teach the content of the lessons they prepared to their peers. A third university also requested that pre-service teachers prepare a lesson that targeted a specific content area and grade level. However, one of the courses had a mixed population of students, with some students attending the educational technology course coming from the Psychology or Philosophy Departments. With such a diverse student audience, the content standards and curriculum resources may have received less emphasis.

One of the assignments is to create a lesson on Google docs and they share it, but they don't implement the lesson because they are not all education majors. (UA40-42)

Another essential condition met by five programs was the provision of student-centered approaches. These lecturers prepared courses in which technology was used as an integral part of pre-service teacher learning. In two programs in particular, students investigated problems, collected and analyzed data, drew conclusions, and conveyed results using electronic tools. The other three used authentic experiences in the form of project-based learning. In these settings, too, pre-service teachers were at the center of the learning process creating technological artifacts, which could be used in their future teaching.

A seventh essential condition for technology integration is ongoing assessment. In this regard, none of the lecturers believed their universities assessed pre-service teachers' competencies related to technology except through their courses. Within the course investigated, student outcomes were generally assessed using a variety of authentic assessment techniques as well as traditional paper and pencil exams.

Each assignment has a grade and a percentage. Like most of them are $15 \%$, for example the Picasa web album it is very easy do, it has $5 \%$, the PowerPoint has more work so it is $15 \%$. Then there is a final test, it is $20 \%$. (UA43-45)

Finally, two essential conditions missing from the programs included community support and support policies. No university-school partnerships had been established among any of the participating universities. Furthermore, none of the lecturers knew of policy at the university to support technology-based innovations. Lastly, all lecturers confirmed the absence of any national accreditation, which required student teachers to demonstrate their pedagogical competence related to educational technologies before they obtained licensure.

\section{Discussion and Recommendations}

The analysis of this study focused on identifying the barriers hindering comprehensive technology preparation at seven Lebanese universities. However, it may be important to 
allude to a number of enabling factors that supported the implementation of technology at these universities.

First, an encouraging starting point for many Lebanese universities is that all but one incorporated an educational technology course in their programs. The stand alone strategy adopted by all participating universities is not without its benefits especially when it is carefully designed, incorporates effective instructional approaches (Lambert et al., 2008), and combines pedagogical concepts, knowledge of content, and technology training (Lambert \& Gong, 2010). These courses have positive results on perceived value beliefs, self-efficacy towards integrating technology and technical knowledge and skills (Kay, 2006).

Second, all participants targeted a variety of technology content goals ranging from computer-based software to web 2.0 technologies and internet-based programs which are currently taking lead in classrooms worldwide. Pre-service teachers were exposed to a variety of technological programs and applications which can be tailored for instruction, perhaps even motivating them to investigate further applications after graduation.

Third, the technical support available at these universities was an important enabler as it positively influenced the work of teacher educators within their courses. Pre-service teachers also benefited from the presence of adequate support when using technological tools outside classroom times. At these universities, special units and personnel were responsible for providing technical support. At two universities, these centers were also responsible for teacher educator training.

Fourth, the majority ( $\mathrm{N}=5$ ) of lecturers emphasized hands-on, learner-centered tasks. Constructivist learning opportunities were provided to pre-service teachers through project-based and problem-based learning assignments. Researchers assert that requiring pre-service teachers to prepare technology-enhanced multimedia materials which target specific learning outcomes has the potential to increase their self-efficacy beliefs, knowledge base and professional growth (Seo, Templeton, \& Pellegrino, 2008). When presented to their peers, such authentic experiences provide pre-service teachers with experiences in problem solving and decision-making without the logistical issues associated with application in the field (Ottenbreit-Leftwich et al., 2010). Such experiences also provide pre-service teachers the opportunity to learn by doing, rather than watching technology being used by instructors (Tondeur et al., 2012).

These enabling factors were outweighed by the presence of eight barriers. In the next section, the discussion of barriers is supported by current research findings, which reveal effective strategies on overcoming difficulties to teacher technology preparation within the university context. In this way, each analysis offers recommendations for the Lebanese context and other universities attempting to enhance the effectiveness of their programs.

\subsection{Insufficient Exposure to Technology Training}

With the single course being the common strategy at all seven universities, such exposure to technology integration may be considered insufficient. At two universities, there was heavy emphasis upon mastery of hardware and software functions rather than on using these 
functions for educational purposes.

Researchers contend that such courses may lead to technology learning, but not necessarily to technology use (Kay, 2006). Pre-service teachers may not be able to translate their newly acquired knowledge and skills into effective classroom practices (Choy et al., 2009). They need to apply a range of tools that enhance student learning, with a level of sophistication that goes well beyond what a single educational technology course can offer. Consequently, teachers may not feel prepared to teach in technologically rich environments (Egbert, Paulus, \& Nakamichi, 2002).

However, with the educational technology course only recently taking shape in most of the courses investigated, advocating the elimination of the standalone technology course at this point may seem impractical (Duttdoner, Allen, \& Corcoran, 2006). An alternative to the way technology is currently taught at Lebanese universities would be to divide the actual course into modules spanning the entire three-year program. The first module would target foundational technological skills, and a second module could be offered concurrent with methods courses. Finally, a third module is proposed during pre-service teachers' practicum courses. Lebanese universities must then begin to take further action towards systemic and systematic program-wide integration of technology (Strudler et al., 2003).

\subsection{Failure to Provide Comprehensive Combined Strategies}

Across the universities investigated, only one university combined three strategies. As noted in the literature review, the benefits of adopting combined strategies are the significant gains in attitudes, confidence and use of technology (Kay, 2006). Pre-service teachers need to learn, use and reuse their technological skills within multiple strategies and take part in numerous activities that consolidate their skills. This integrated strategy has also been found to support pre-service teachers' gradual learning of increasingly complex technological skills as they progress through the program and apply these skills in their practicum courses (Collier et al., 2004).

Therefore, Lebanese universities are encouraged to incorporate a more integrated approach that builds on the Technological, Pedagogical and Content Knowledge (TPACK) framework (Mishra \& Koehler, 2006). Guided by the need to incorporate a more integrated approach that merges content, pedagogy and technology, teacher educators should incorporate technology preparation throughout teacher education curricula (Angeli \& Valanides, 2009).

\subsection{Differences in the Access to Technology Resources}

All seven universities differed in the technological resources available. Only two universities placed emphasis on the access strategy, which addressed the need for hardware, software and support. Lebanese universities must ensure that their pre-service teachers have access to a variety of technological tools that are commonly found and used at schools. This is a critical enabling factor that increases the probability of teaching and learning with technology (Strudler et al., 2003).

Furthermore, all lecturers noted conducting their courses in a computer lab, rather than a 
normal classroom. Unlike a typical classroom, the computer lab normally has fixed positions, limited sightlines, and does not offer the flexibility of physical movement. With restricted access to technology at some of these universities, and without robust technological infrastructure, effective uses of technology become difficult. Furthermore, without such access, other strategies, specifically the integrated strategy, are bound to fail (Kay, 2006). As part of a comprehensive plan, Lebanese universities are required to allocate resources to new equipment and resources.

\subsection{Lack of a Shared Vision and Compartmentalization of Educational Technology Courses}

None of the Lebanese universities investigated had university-wide policies that promoted the integration of technology. A lack of policies resulted in the compartmentalization of education courses and prevented the cooperation of teacher educators. Researchers contend that a university-wide policy supports systemic and systematic change efforts to take shape over time (Tondeur et al., 2012). Based on research findings, Lebanese universities need a technology plan that is collectively designed by all teacher educators, supported technically and instructionally by specialized team members, aimed at the empowerment of teacher educators, and constantly updated (Goktas, Yildirim, \& Yildirim, 2009).

\subsection{Lack of Mastery and Vicarious Experiences}

Six universities required that their pre-service teachers complete a field-based component; however, the field experience was not connected to the educational technology course. Research consistently points to the importance of field sites where teachers can observe and actively participate in effective uses of technology (Brush et al., 2003). To take advantage of field-based strategies, teacher educators must begin to establish robust partnerships with schools known for their integration of technology in different subjects. Such sites present teachers with opportunities to gain mastery and vicarious experiences which enhance their self-efficacy beliefs towards technology (Wang, Ertmer, \& Newby, 2004). When such sites are totally unavailable, mentor teachers could be brought into the university classroom through web resources that show effective examples of technology being used in real settings (Wang, Ertmer, \& Newby, 2004). Being able to manipulate the video adds further benefits resulting from analyzing and evaluating the lessons observed (Ottenbreit-Leftwich et al., 2010).

\subsection{Insufficient Professional Development for Teacher Educators}

With only two universities offering professional development for their teacher educators, this study suggests that not all teacher educators possessed the knowledge, skills and self-efficacy beliefs required to teach or model technology integration to pre-service teachers. Other studies conclude that teacher educators' level of proficiency with technology is considered a major barrier to technology integration at the university level (Mims et al., 2006). In designing professional development for faculty, Lebanese universities must ensure that they are ongoing, content-focused, site-based and involve teacher educators as active learners (Strudler et al., 2003). Also recommended is the establishment of an instructional technology center that models the use of technological tools, integrates them into courses and offers 
training on a regular basis (Goktas et al., 2009).

\subsection{Lack of Clear Focus on One Subject Matter and/or Grade Level}

Most of the participating universities had pre-service teachers take the educational technology course without considering the subject area discipline or the grade level they will teach. Therefore, pre-service teachers majoring in English language sat alongside mathematics majors while primary pre-service teachers took the same course as secondary teachers. Researchers contend that each subject area creates a specialized community of practice that consists of particular literacies communicated among its members (Gomez et al., 2008). Skills-based courses taught in isolation of subject-specific contexts fail to establish pedagogical connections between the affordances of technology and the teaching of specific content (Angeli \& Valanides, 2009). Further, different educational programs are designed to accomplish specific goals and are compatible with different grade levels, requiring that clear distinctions be made between the technological tools appropriate for older learners and those more suitable for a younger audience. Given the importance of this distinction, teacher educators should divide their classes according to the professional needs of their student teachers.

\subsection{Limited Scope in the Assessment of Technological Skills}

Within the courses investigated, pre-service teachers were assessed using rubrics for their projects and traditional paper and pencil assessment. None of the lecturers mentioned program-wide or nation-wide evaluations of graduating teachers' technology competencies. In order to encourage further development and improvement, teacher educators should collect continuous feedback about course outcomes before, during and/or after the course. Teacher educators can collect data through discussions, questionnaires, interviews and observations (Lambert \& Gong, 2010). They can examine pre-service teachers' competencies in using technology and their self-efficacy beliefs, as well as the effectiveness of the strategies adopted and their own educational technology competencies (Lavonen et al., 2006).

\section{Conclusion}

The study examined seven university educational technology courses by interviewing the teacher educator responsible for developing and teaching this course. The broader context of technology integration for all seven courses was the standalone educational technology course. The course was one of many other courses, which formed the program of study. The strategies used within these courses differed to some extent; however, common to all courses was the single course strategy. None of the universities used the field-based, mentor teacher, collaboration, integrated or workshop strategy. The approaches to technology integration included authentic experiences $(\mathrm{N}=5)$, information delivery $(\mathrm{N}=4)$, hands-on skill building $(\mathrm{N}=3)$ and observations and models $(\mathrm{N}=1)$.

Participating universities met several important conditions for the creation of a university environment conducive to technology integration. However, none of the universities met all 
ten conditions. In general, the commitment of the university towards technology integration was more at the course-level than the university level. All seven lecturers displayed commitment towards delivering an appropriate course in educational technology, despite limitations in resources available and strategies possible. Other limitations were imposed upon them from the schools in which their pre-service teachers conducted practicum courses. With limited availability of mentors outside the course, teacher trainers could not always create university-school partnerships, which would ensure the trialability and observability of technology integration in action.

This study has offered useful insight into the uneven progress that has marked the integration of technology into universities in Lebanon, through its examination of provision of technology education for pre-service teachers, and has offered recommendations for forward direction. It points to the need for further research In the Lebanese university context. Teacher educators should conduct evidence-based research to identify the weaknesses and strengths in their courses, and identify the effects on student teacher learning. The observation of which strategies, approaches and content goals correlate with higher levels of technology use by their student teachers will be a powerful step forward.

\section{References}

Angeli, C, \& Valanides, N. (2009). Epistemological and methodological issues for the conceptualization, development, and assessment of ICT-TPCK: Advances in technological pedagogical content knowledge (TPCK). Computers and Education, 52(1), 154-169. http://dx.doi.org/10.1016/j.compedu.2008.07.006

Brush, T., Glazewski, K., Rutowski, K., Berg, K., Stromfors, C., Van-Nest, M. H., ... \& Sutton, J. (2003). Integrating technology in a field-based teacher training program: The PT3@ ASU project. Educational Technology Research and Development, 51(1), 57-72.

Campbell, C., \& Kent, P. (2010). Using interactive whiteboards in pre-service teacher education: Examples from two Australian universities. Australasian Journal of Educational Technology, 26(4), 447-463.

Choy, D., Wong, A. F., \& Gao, P. (2009). Student Teachers' Intentions and Actions on Integrating Technology into Their Classrooms during Student Teachings: A Singapore Study. Journal of Research on Technology in Education, 42(2), 175-195. http://dx.doi.org/10.1080/15391523.2009.10782546

Collier, S., Weinburgh, M. H., \& Rivera, M. (2004). Infusing technology skills into a teacher education program: Change in students' knowledge about and use of technology. Journal of Technology and Teacher Education, 12(3), 447.

Creswell, J. W. (2013). Research Design: Qualitative, Quantitative, and Mixed Methods Approaches: Sage Publications.

Denzin, N. K, \& Lincoln, Y. S. (1998). Collecting and interpreting qualitative materials. California: SAGE. 
Duttdoner, K., Allen, S. M., \& Corcoran, D. (2005). Transforming student learning by preparing the next generation of teachers for type II technology integration. Computers in the Schools, 22(3-4), 63-75. http://dx.doi.org/10.1300/J025v22n03_06

Egbert, J., Paulus, T. M., \& Nakamichi, Y. (2002). The impact of CALL instruction on classroom computer use: A foundation for rethinking technology in teacher education. Language Learning \& Technology, 6(3), 108-126.

Goktas, Y., Yildirim, S., \& Yildirim, Z. (2009). Main Barriers and Possible Enablers of ICTs Integration into Pre-service Teacher Education Programs. Educational Technology \& Society, 12(1), 193-204.

Gomez, L.M., Sherin, M. G., Griesdorn, J., \& Finn, L. E. (2008). Creating social relationships: The role of technology in preservice teacher preparation. Journal of Teacher Education, 59(2), 117-131. http://dx.doi.org/10.1177/0022487107314001

Hsu, P. S. (2012). Examining the impact of educational technology courses on pre-service teachers' development of technological pedagogical content knowledge. Teaching Education, 23(2), 195-213. http://dx.doi.org/10.1080/10476210.2011.622041

ISTE. (2008). The ISTE national educational technology standards (NETS•T) and performance indicators for teachers. Eugene, OR: International Society for Technology in Education.

Kay, R. H. (2006). Evaluating strategies used to incorporate technology into preservice education: A review of the literature. Journal of research on technology in education, 38(4), 383-408. http://dx.doi.org/10.1080/15391523.2006.10782466

Lambert, J., \& Gong, Y. (2010). 21st century paradigms for pre-service teacher technology $\begin{array}{llll}\text { preparation. } \quad \text { Computers in the Schools, 27(1), } & \text { 54-70. }\end{array}$ http://dx.doi.org/10.1080/07380560903536272

Lambert, J., Gong, Y., \& Cuper, P. (2008). Technology, transfer, and teaching: The impact of a single technology course on preservice teachers' computer attitudes and ability. Journal of Technology and Teacher Education, 16(4), 385.

Lavonen, J., Lattu, M., Juuti, K., \& Meisalo, V. (2006). Strategy - based development of teacher educators' ICT competence through a co - operative staff development project. European Journal of Teacher Education, 29(2), 241-265. http://dx.doi.org/10.1080/02619760600617433

MEHE. (2012). Teaching and Learning in the Digital Age: Lebanon's National Educational Technology Strategic Plan. Beirut: Lebanon: The Ministry of Education and Higher Education Strategic Planning Development Team. Retrieved from http://www.mehe.gov.lb/Uploads/file/TLSP.pdf

Mims, C., Polly, D., Shepherd, C., \& Inan, F. (2006). Examining PT3 projects designed to improve preservice education. TechTrends, 50(3), 16-24. http://dx.doi.org/10.1007/s11528-006-7599-5 
Mishra, P., \& Koehler, M. (2006). Technological pedagogical content knowledge: A framework for teacher knowledge. The Teachers College Record, 108(6), 1017-1054.

Ottenbreit-Leftwich, A., Glazewski, K., \& Newby, T. (2010). Preservice technology integration course revision: A conceptual guide. Journal of Technology and Teacher Education, 18(1), 5-33.

Partnership for 21st Century Skills. (2010). 21st century knowledge and skills in educator preparation. American Association of Colleges for Teacher Education; Partnership for 21st Century Skills. http://files.eric.ed.gov/fulltext/ED519336.pdf

Saleh, H. (2007). Instructional Technology Barriers and Computer Self-Efficacy of University Faculty in Lebanon. Paper presented at the Society for Information Technology \& Teacher Education International Conference 2007, San Antonio, Texas, USA. http://www.editlib.org/p/24838

Seo, K. K., Templeton, R., \& Pellegrino, D. (2008). Creating a ripple effect: Incorporating multimedia-assisted project-based learning in teacher education. Theory Into Practice, 47(3), 259-265. http://dx.doi.org10.1080/00405840802154062

Strudler, N., Archambault, L., Bendixen, L., Anderson, D., \& Weiss, R. (2003). Project THREAD: Technology helping restructure educational access and delivery. Educational Technology Research and Development, 51(1), 41-56. http://dx.doi.org/10.1007/BF02504517

Tondeur, J., van Braak, J., Sang, G., Voogt, J., Fisser, P., \& Ottenbreit-Leftwich, A. (2012). Preparing pre-service teachers to integrate technology in education: A synthesis of qualitative evidence. Computers \& Education, 59(1), 134-144. http://dx.doi.org/10.1016/j.compedu.2011.10.009

UNESCO. (2002). Information and Communication Technologies in Teacher Education: A Planning Guide. Paris: UNESCO.

Wang, L., Ertmer, P. A., \& Newby, T. J. (2004). Increasing preservice teachers' self-efficacy beliefs for technology integration. Journal of Research on Technology in Education, 36(3), 231-250. http://dx.doi.org/10.1080/15391523.2004.10782414

Wang, Y. M. (2006). Stand-alone computer courses in teachers' IT training. Educause Quarterly, 29(3), 8.

\section{Copyright Disclaimer}

Copyright for this article is retained by the author(s), with first publication rights granted to the journal.

This is an open-access article distributed under the terms and conditions of the Creative Commons Attribution license (http://creativecommons.org/licenses/by/3.0/). 